\title{
Determinantes da satisfação e atributos da qualidade em serviços bancários
}

\section{Satisfaction determinants and quality attributes in bank services}

\author{
José Luis Duarte Ribeiro' \\ Cássio Oliveira Machado' \\ Maria Auxiliadora Cannarozzo Tinoco ${ }^{1}$
}

\begin{abstract}
Resumo: A qualidade percebida e a satisfação dos clientes são elementos essenciais para a competitividade das instituições bancárias. Assim, é importante identificar os fatores que determinam a percepção de qualidade e satisfação do ponto de vista dos clientes que utilizam esse tipo de serviço. O objetivo deste artigo é a construção de um modelo de relacionamento entre os determinantes de satisfação de clientes e a identificação dos principais atributos que afetam a qualidade percebida dos clientes de serviços bancários. Para isto, foram aplicadas duas pesquisas descritivas. Na primeira fase das pesquisas, utilizou-se a abordagem proposta por Tinoco e Ribeiro (2007) para identificar as relações entre determinantes e construir o modelo de satisfação de clientes. Na segunda fase, foram levantados e hierarquizados os principais atributos de qualidade percebida do ponto de vista dos clientes. Entre os resultados obtidos destacam-se como principais determinantes da satisfação de clientes a confirmação de expectativas e a qualidade percebida. Entre atributos mais importantes que afetam a qualidade percebida podem ser citados: funcionários com conhecimento e habilidade devidos, serviço feito corretamente na primeira vez, tarifas bancárias baratas, transparência e lealdade nas negociações, e presença de funcionários que buscam tornar o serviço mais ágil.
\end{abstract}

Palavras-chave: Satisfação de clientes. Atributos da qualidade. Serviços bancários.

\begin{abstract}
Perceived quality and customer satisfaction are essential elements for competitiveness of banking institutions. Therefore, it is important to identify customers' view of banks about drivers of quality perception and satisfaction. This paper presents a relationship model of determinant factors of satisfaction and the identification of key quality attributes for bank services. The model was built conducting two customer surveys. Firstly, the approach proposed by Tinoco and Ribeiro(2007) was applied to identify the relationship among the determinants and to build a satisfaction model. Next, main quality attributes considering the customer's view were surveyed and ranked. The results indicate that the confirmation of expectations and perceived quality are the most important determinants for customer satisfaction. Among the most important attributes that affect perceived quality, the following were highlighted: employees with proper knowledge and abilities, service done correctly in the first attempt, low bank tariffs, transparency and loyalty in transactions, and presence of employees providing agile services.
\end{abstract}

Keywords: Customer satisfaction. Quality attributes. Bank services.

\section{Introdução}

A qualidade percebida e a satisfação dos clientes no setor de serviços vêm sendo amplamente estudadas, pois influenciam as intenções de compra, a retenção dos clientes e, em consequência, a geração de lucro para as empresas (LOVELOCK; WRIGHT, 2001; FITZSIMMONS, J. A.; FITZSIMMONS, M., 2000).

A indústria bancária é um ambiente caracterizado pelo grande envolvimento entre clientes e provedor do serviço. Para atender às necessidades, em constante mudança, de seus clientes as instituições bancárias precisam se reestruturar rapidamente, respondendo ao mercado e às novas tecnologias que surgem.
A satisfação dos clientes é alcançada por aquelas instituições que conseguem promover continuamente a melhoria da qualidade dos serviços prestados (ARASLI; MEHTAP-SMADI; KATIRCIOGLU, 2005).

A satisfação do cliente é um ponto crítico nos setores industriais de maior competitividade. Garantir a satisfação do cliente não garante, contudo, a sua fidelidade. Clientes meramente satisfeitos podem ser atraídos pelos concorrentes, enquanto clientes totalmente satisfeitos apresentam um comportamento mais fiel (LOVELOCK; WRIGHT, 2001).

\footnotetext{
Departamento de Engenharia de Produção e Transportes, Universidade Federal do Rio Grande do Sul - UFRGS, Av. Osvaldo Aranha, 99, $5^{\circ}$ andar, CEP 90035-190, Porto Alegre - RS, Brasil,

E-mails: ribeiro@producao.ufrgs.br; machado_cassio@producao.ufrgs.br; maria@producao.ufrgs.br
} 
Levesque e McDougall (1996) afirmam que, no setor de serviços bancários, a maior satisfação e lealdade dos clientes proporcionam ao banco reduzir seus custos operacionais, uma vez que diminuem tanto a necessidade de abertura e fechamento de contas, quanto a necessidade de avaliações de crédito. Manter bons clientes por um longo período permite à empresa um maior conhecimento de suas preferências e necessidades de produtos bancários, fornecendo-lhes um atendimento direcionado e eficiente. Além disso, clientes habituados aos serviços da empresa estarão mais propensos à aquisição de novos produtos ou serviços que sejam oferecidos.

O presente artigo apresenta a construção de um modelo para a satisfação dos clientes de serviços bancários, por meio da identificação das relações entre os determinantes da satisfação, conforme propostos por Tinoco e Ribeiro (2007). Além disso, sendo a qualidade percebida um dos principais determinantes da satisfação dos clientes de serviços (FORNELL et al., 1996; ANDREASSEN; LINDESTAD, 1998; BEI; CHIAO, 2001; CHOI et al., 2004; TINOCO, 2006), este trabalho identifica os principais atributos de qualidade percebida para o serviço em estudo.

Após esta introdução, a seção 2 apresenta conceitos importantes referentes a modelos e determinantes da satisfação de clientes e qualidade percebida. A seção 3 apresenta os conceitos de qualidade em serviços bancários. A seção 4 detalha os procedimentos metodológicos utilizados no estudo. A seção 5 apresenta o estudo aplicado, e a seção 6 sumariza as principais conclusões do estudo e suas implicações teóricas e práticas.

\section{Modelos e determinantes para satisfação do cliente}

A satisfação do cliente pode ser avaliada como uma combinação de diversos determinantes relacionados à prestação do serviço, sendo os mais utilizados a qualidade do serviço, a confirmação de expectativas e o desempenho em transações individuais (LEVESQUE; McDOUGALL, 1996).

Pesquisas sobre satisfação utilizaram amplamente a confirmação de expectativas como base para os modelos construídos. Oliver (1980) foi um dos primeiros autores a incluir estudos sobre a confirmação de expectativas no modelo de satisfação do cliente. Contudo, a visão de satisfação como resultado do gap entre expectativas e desempenho é adotada por diversos autores (e.g., CHURCHILL; SURPRENANT, 1982; YI, 1993; OLIVER, 1993).

A natureza do contexto em que o serviço é prestado pode influenciar diretamente a confirmação de expectativas. Em alguns casos, o serviço pode ter características de difícil avaliação, o que possibilita que expectativas, desempenho, e o gap resultante, tenham maior ou menor efeito na satisfação. Além disso, fatores cognitivos relacionados à prestação do serviço também podem influenciar a satisfação do cliente (BEARDEN; TEEL, 1983; CADOTTE; WOODRUFF; JENKINS, 1987; LEVESQUE; McDOUGALL, 1996).

Os modelos para a satisfação dos clientes têm sido estudados e modificados por diversos autores, que passaram a incluir outros determinantes ao modelo de confirmação de expectativas ou desenvolveram estudos avaliando diretamente a relação de certos determinantes com a satisfação do consumidor. Oliver (1993) e Jun et al. (2001) incorporaram paradigmas afetivos (positivo e negativo) ao modelo de confirmação de expectativas. Segundo esses autores, as experiências do dia a dia podem gerar nas pessoas diferentes tipos de afetos que influenciam a percepção do cliente. Alguns modelos consideram que, além de expectativas, os desejos dos clientes também seriam um importante contribuinte para a satisfação. Segundo Spreng, Mackenzie e Olshsky (1996), a satisfação do cliente é influenciada pela satisfação com as características do produto ou serviço em si e pela satisfação com a informação utilizada na sua escolha. Imagem corporativa, valor e qualidade foram também avaliados como fatores que podem influenciar a satisfação. O modelo proposto por Andreassen e Lindestad (1998) propõe que qualidade e imagem corporativa teriam grande influência na satisfação, enquanto o valor não afetaria significativamente. $\mathrm{O}$ valor não é necessariamente antecedente ou consequência da satisfação, e nem sempre é considerado pelo cliente durante a escolha. A estimação de valor é afetada pelas expectativas do cliente e, além disso, é mais fácil estimar o valor de um produto do que de um serviço (DAY, 2002). Contudo, outras pesquisas revelam que o valor percebido pode ter significância na satisfação, tanto diretamente como indiretamente, por meio de outros determinantes. Por exemplo, Cronin Junior, Brady e Hult (2000) apontam que tanto a qualidade quanto o valor do serviço são antecedentes significantes da satisfação, porém com a qualidade exercendo maior influência em alguns casos.

Muitas pesquisas estudaram e vêm estudando o relacionamento entre os determinantes mencionados. Contudo, é evidente que, perante o grande número de aspectos a serem considerados, existe uma carência de estudos que relacionem simultaneamente o conjunto de determinantes. Grande parte dos estudos existentes relaciona pequenos grupos de determinantes.

Tinoco e Ribeiro (2007) propõem uma nova abordagem para modelar a satisfação de clientes de serviços, pela identificação das relações entre múltiplos determinantes encontrados na literatura. Essa abordagem caracteriza-se por: i) utilização de procedimentos estatísticos mais simples em 
relação aos métodos tradicionais de modelagem; ii) possibilidade de identificar relações entre múltiplos determinantes utilizando um tamanho de amostra relativamente pequeno (pelo menos 40 clientes); e iii) ampla abrangência, pois consideram um maior número de variáveis relevantes sem tornar o modelo muito complexo. Os autores aplicaram a abordagem proposta para modelar a satisfação de clientes com serviços de restaurante à la carte, obtendo o modelo apresentado na Figura 1.

Conforme esses autores, a base do modelo de satisfação de clientes com restaurantes à la carte está fundamentada no relacionamento entre a qualidade percebida, a confirmação de expectativas e a satisfação. A satisfação gera novas expectativas nos clientes, as quais influenciam os desejos pessoais. Esses desejos afetam as emoções vivenciadas no momento da prestação de serviço, as quais por sua vez, influenciam na satisfação do cliente. A satisfação do cliente junto com a percepção de qualidade são os responsáveis pela imagem corporativa e a percepção de valor do serviço (TINOCO; RIBEIRO, 2007). Uma breve definição de cada determinante é apresentada na sequência.

As expectativas dos clientes são as crenças sobre os atributos ou desempenho de um produto ou serviço em qualquer momento no futuro. Essas crenças são formadas pelas experiências de consumo anteriores, incluindo as adquiridas por meio de propaganda boca a boca e as informações do fornecedor desse produto ou serviço e seus concorrentes (OLIVER, 1980; CHURCHILL; SURPRENANT, 1982; BEARDEN; TEEL, 1983; KOTLER; KELLER, 2006; FORNELL et al., 1996).

Os desejos são os níveis de atributos ou benefícios que o consumidor almeja alcançar com a aquisição de um produto ou serviço. Estão relacionados a carências por satisfações específicas para atender às necessidades pessoais e são continuamente moldados e adaptados aos padrões da sociedade
(SHETH; BANWARI; NEWMAN, 2001; SPRENG; MACKENZIE; OLSHAVSKY, 1996; KOTLER, 1998).

Sheth, Banwari e Newman (2001) definem as emoções como a consciência da ocorrência de alguma excitação fisiológica seguida por uma resposta comportamental e uma avaliação cognitiva. Estas emoções orientam as ações do dia a dia das pessoas e são geradas por estímulos que podem vir do ambiente externo e também de dentro do organismo (ansiedade, fome, dor de cabeça).

A confirmação de expectativas é resultado da comparação entre as expectativas prévias do cliente e o desempenho real do serviço, na percepção desse cliente (OLIVER, 1980; CHURCHILL; SURPRENANT, 1982).

O preço, do ponto de vista do consumidor, é definido como aquilo do qual se renuncia ou que é sacrificado na obtenção de um produto. Quando o cliente percebe que o preço de um produto ou serviço é razoável, ele se sentirá satisfeito e manifestará intenções de repetir a compra. Por outro lado, se o consumidor sente que seu sacrifício não vale a pena, ele poderá não repetir a compra, mesmo que esteja satisfeito com a qualidade do produto ou serviço (BEI; CHIAO, 2001; ZEITHAML, 1988).

O valor percebido pelo cliente é resultado da avaliação dos benefícios percebidos com o produto ou serviço em relação aos sacrifícios despendidos na sua aquisição (ZEITHAML, 1988; CHOI; CHO; LEE, 2004; ANDREASSEN; LINDESTAD, 1998).

A imagem corporativa é definida como as percepções, sobre uma organização, que são fixadas na memória do consumidor. Quanto mais forte for a imagem corporativa mais chances a empresa tem de enfrentar as crises, especialmente as relacionadas com credibilidade e confiança na organização, ou seja, a conduta da empresa tem um impacto significativo sobre as percepções do público (KOTLER; KELLER, 2006; SHETH et al., 2001).

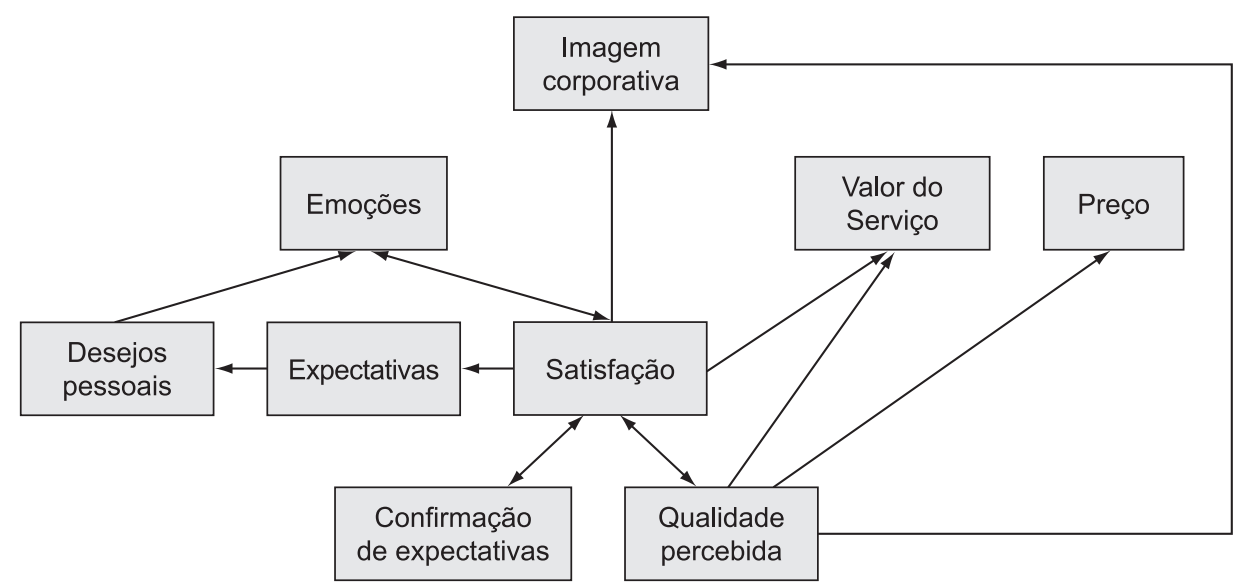

Figura 1. Modelo de causa e efeito da satisfação dos clientes para restaurantes à la carte. Fonte: Adaptado de Tinoco e Ribeiro (2007). 
A qualidade percebida pode ser definida como a avaliação do cliente da excelência do produto ou serviço em uma experiência recente de consumo (FORNELL et al., 1996; TINOCO; RIBEIRO, 2008).

Em serviços, a qualidade é gerada como resposta a um processo de avaliação, em que o consumidor compara suas expectativas prévias em relação ao serviço com a sua percepção do serviço (GRÖNROOS, 1984; PARASURAMAN; ZEITHAML; BERRY, 1985). Ao longo de anos, a qualidade em serviços vem sendo estudada por muitos pesquisadores, com diversas abordagens. Porém, alguns modelos propostos tiveram maior reconhecimento e utilização.

Grönroos (1984) foi um dos primeiros pesquisadores a propor um modelo para a avaliação da qualidade em serviços. Segundo esse autor, a qualidade percebida é função do serviço esperado, do serviço percebido e da imagem da empresa. De acordo com o modelo proposto, as dimensões ou os determinantes que são avaliados quando o consumidor adquire um serviço são: qualidade técnica, avaliada como aquilo que o cliente recebe durante a aquisição do serviço e qualidade funcional, relacionada ao desempenho do serviço observado pelo cliente de forma subjetiva. A imagem constitui a terceira dimensão de qualidade do modelo e abrange o local e os recursos disponíveis durante o consumo. Ela é construída pelas qualidades técnica e funcional, além de outros fatores como reputação, informações de terceiros, propaganda, preço e relações públicas (GALLOWAY; BLANCHARD, 1996; SETH; DESHMUKH; VRAT, 2004; TINOCO; RIBEIRO, 2008).

Um dos modelos amplamente utilizados para a medição da qualidade em serviços é o modelo SERVQUAL, criado por Parasuraman, Zeithaml e Berry (1985; 1988), originalmente contendo 10 dimensões para a qualidade. O modelo sofreu modificações ao longo dos anos e foi reduzido a cinco dimensões principais: Aspectos Tangíveis - instalações, equipamentos e pessoal envolvido; Confiabilidade capacidade de prover o serviço prometido de forma confiável e precisa; Presteza - disponibilidade para ajudar o cliente e prestar um serviço adequado; Segurança - habilidade em transmitir confiança e segurança, com cortesia e conhecimento do serviço; e Empatia - cuidados e atenção individualizados, que a empresa proporciona aos seus clientes. Diversos estudos utilizaram o modelo SERVQUAL como base para a criação de novos instrumentos e comparações entre eles. Cronin e Taylor (1992) desenvolveram um modelo, baseado no trabalho de Parasuraman, Zeithaml e Berry (1985), que somente considera a avaliação de desempenho do serviço como a forma mais apropriada de medir a qualidade. $\mathrm{O}$ trabalho desses autores é conhecido por modelo SERVPERF, sendo também encontrado na literatura como Performance only model (SETH; DESHMUKH; VRAT, 2004). Os autores afirmam que qualidade percebida seria mais bem conceituada como uma "atitude" e que o modelo SERVPERF seria mais eficaz na operacionalização da qualidade dos serviços do que o modelo SERVQUAL, possibilitando que a qualidade fosse mais bem analisada (MIGUEL; SALOMI, 2004).

Segundo Blanchard e Galloway (1994), os modelos propostos por Grönroos (1984) e por Parasuraman, Zeithaml e Berry (1985) têm uma abordagem superficial, visto que oferecem um grande número de itens que permitem medir a qualidade, porém não oferecem ao provedor de serviço variáveis que sejam usuais e características do serviço oferecido.

\section{Qualidade em serviços bancários}

No cenário econômico brasileiro atual, caracterizado pela busca de novos mercados, além da criação e disseminação de conhecimento, os bancos exercem o papel de agentes de desenvolvimento da sociedade. Apesar da alta competitividade do setor, existe um equilíbrio entre as empresas que oferecem os benefícios, as quais competem muitas vezes pelos mesmos clientes. De acordo com o Relatório Social da FEBRABAN - Federação Brasileira de Bancos, o volume de serviços prestados à sociedade pelo setor bancário é expressivo e crescente. Ao longo dos últimos anos, o sistema financeiro expandiu seu atendimento a muitos municípios brasileiros. Os bancos interagem com todos os setores da sociedade e estão mais acessíveis a todos esses segmentos. O contato com os clientes é fundamental para os bancos avaliarem sua atuação e a percepção do público sobre eles, bem como identificarem as principais demandas e oportunidades de melhoria ou inovação (FEDERAÇÃO..., 2006).

Avanços tecnológicos permitem disponibilizar novos serviços, promovendo assim a bancarização de milhões de brasileiros, além de maior comodidade e segurança a todos os clientes e usuários das instituições. $\mathrm{O}$ equilíbrio entre bancos nacionais (públicos ou privados) e estrangeiros também auxiliou na formação de um cenário de instituições modernas e competitivas, fundamental para estimular o crescimento da economia brasileira (FEDERAÇÃO..., 2007).

Considerando a existência de muitas instituições, e a estabilidade das relações com os clientes, a expansão dos negócios se dará mediante a diferenciação. A forma como os bancos prestam seus serviços atualmente oferece grandes oportunidades para atrair e manter clientes, os quais estão em busca de produtos e serviços que satisfaçam suas necessidades. A diferenciação entre os fornecedores de um serviço, por vezes, se dá pela melhoria da qualidade de seus produtos e serviços, o que irá gerar maior satisfação de seus clientes (FEDERAÇÃO..., 2006; LEVESQUE; McDOUGALL, 1996). 
Em relação à avaliação da qualidade em serviços bancários, desde a década de 90, o modelo SERVQUAL vem sendo testado e analisado dentro da indústria bancária, envolvendo aplicações do modelo, comparação com outros métodos e inclusive desenvolvimento de outros instrumentos (GUO; DUFF; HAIR, 2008). Os estudos relacionados ao modelo SERVQUAL que originaram novas ferramentas dentro da área de serviços bancários são variados, conforme relatado a seguir.

Avkiran (1994) criou a ferramenta chamada escala BANKSERV, que contempla 17 itens referentes ao setor bancário, para a qual propõe uma abordagem em quatro dimensões: Conduta do pessoal envolvido responsabilidade, conduta civilizada e apresentação de pessoal preparado para prover um serviço profissional; Confiabilidade - relação leal com o cliente, informação clara e eficiência na reparação de erros; Comunicação manter o cliente informado sobre os procedimentos que estão ocorrendo e buscar a compreensão das suas necessidades; e Acesso ao serviço de caixa - adequação do número de atendentes e caixas em horários de maior movimento e disponibilidade de autoatendimento.

Bahia e Nantel (2000) criaram o modelo BSQ, Banking Services Quality, que é uma escala alternativa para a mensuração da qualidade percebida, tomando como base a escala SERVQUAL, à qual os autores adicionaram e modificaram dimensões envolvidas para avaliação da qualidade, buscando uma abordagem mais profunda e fiel ao contexto de serviços bancários. Contudo, nesse mesmo estudo, os autores comprovam que o BSQ não pode ser considerado um instrumento independente do SERVQUAL. O BSQ é composto por 31 itens, divididos em seis dimensões (BAHIA; NANTEL, 2000): Efetividade e segurança; Acesso e caixas eletrônicos; Preço; Aspectos tangíveis; Portfólio de serviços; e Confiabilidade.

Observa-se uma série de estudos para medição da qualidade dentro de várias abordagens e contextos. Alguns resultados sugerem que a aplicabilidade de um modelo será influenciada pelo cenário do serviço ao qual ele é submetido, criando a necessidade de avaliação das características de cada serviço oferecido.

\section{Procedimentos metodológicos}

No presente trabalho, a modelagem da satisfação dos clientes de serviços bancários, envolvendo a identificação das relações entre os determinantes neste setor específico, foi realizada utilizando a abordagem proposta por Tinoco e Ribeiro (2007). A metodologia estabelecida para identificar as relações entre determinantes e os atributos mais importantes de qualidade percebida nos serviços bancários, envolve levantamentos (surveys) junto aos clientes, conduzidas em duas fases: i) identificação de relações entre determinantes e ii) identificação e hierarquização dos atributos de qualidade percebida.
Tinoco e Ribeiro (2007) consideram que uma amostra de pelo menos 40 respondentes é suficiente para obter relações significativas no modelo. Esse tamanho de amostra mostrou-se suficiente para revelar várias relações estatisticamente significativas entre determinantes (o que não aconteceria se o tamanho da amostra fosse insuficiente). Neste trabalho, as amostras de cada levantamento foram constituídas de 50 usuários de serviços bancários, envolvendo homens e mulheres de diferentes faixas etárias, que possuíam ensino médio concluído. Esses critérios foram utilizados em função da terminologia relativamente complexa. Atendidos os requisitos de possuir ensino médio concluído e ser usuário de serviços bancários, os respondentes foram selecionados aleatoriamente, de forma a estabelecer uma amostra diversificada no que tange a sexo, idade, classe social e estabelecimento frequentado. As pesquisas ocorreram em um curto espaço de tempo, porém não simultaneamente, sendo que uma pequena parte dos entrevistados respondeu a ambas. Ambos os levantamentos foram realizados no Estado do Rio Grande do Sul, especificamente na cidade de Porto Alegre.

É importante esclarecer que o presente estudo está focado na modelagem da satisfação de clientes e na identificação dos principais atributos de qualidade percebida para serviços gerais oferecidos por instituições bancárias, sem fazer distinção entre tipos de clientes ou serviços.

\subsection{Identificação de relações entre determinantes}

A primeira fase envolve a identificação das relações existentes entre os determinantes do modelo de satisfação do consumidor. Conforme a proposta de Tinoco e Ribeiro (2007), esta fase contempla as etapas: i) definição dos determinantes, ii) aplicação da pesquisa e iii) construção do modelo.

A definição dos determinantes não está no escopo do presente estudo, uma vez que foram utilizados os mesmos determinantes sugeridos pelos autores. $\mathrm{O}$ critério de escolha para selecionar os determinantes a serem avaliados na abordagem proposta por Tinoco e Ribeiro (2007) fundamentou-se no estudo dos principais modelos e determinantes de satisfação encontrados na literatura e considerados na maioria das pesquisas. Desta forma, os determinantes contemplados para a modelagem da satisfação de clientes de serviços bancários são: satisfação gerada pelo serviço, qualidade percebida, expectativas, desejos, emoções, confirmação de expectativas, preço, valor percebido e imagem corporativa. A aplicação da pesquisa é feita por meio de um questionário fechado (Anexo A) contendo nove questões que objetivam avaliar as relações de dependência entre cada um dos nove determinantes para com os demais. Durante 
a aplicação do questionário, são apresentados os conceitos de cada um dos determinantes (Anexo B) e é solicitado ao respondente que assinale, para cada determinante, se ele depende diretamente dos demais. Por exemplo, a imagem corporativa depende principalmente de satisfação, qualidade percebida, desejos pessoais, etc. ou, então, a satisfação depende principalmente de qualidade percebida (sendo que os respondentes podem assinalar que o determinante em questão não depende de nenhum dos demais, ou de todos eles).

Para a construção do modelo, a contagem das respostas assinaladas nos questionários é colocada em uma matriz para permitir a determinação das relações significativas entre os determinantes. As relações significativas são definidas a partir da análise dos resíduos padronizados, calculados utilizando-se a Equação 1 (AGRESTI; FINLEY, 1997 apud TINOCO; RIBEIRO, 2007):

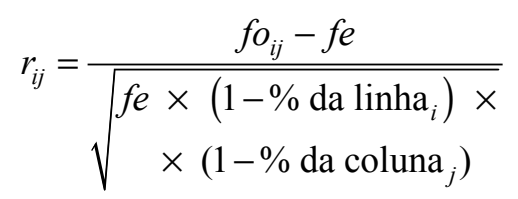

em que:

$r_{\mathrm{ij}}$ : resíduo padronizado para a relação $i j$;

$f o_{\mathrm{ij}}$ : valor observado (contagem obtida para a relação $i j)$;

$f e$ : valor esperado (média dos valores observados); $\%$ da linha $a_{\mathrm{i}}$ c contagem da linha i/contagem total; e $\%$ da coluna: contagem da coluna j/contagem total.

Resíduos padronizados maiores do que $+2,0$ indicam relações significativas, considerando o nível de confiança usualmente utilizado em estudos de engenharia e ciências sociais, alfa $=0,05$. Obtidas as relações significativas, é construído o diagrama de causa e efeito que representa o modelo de satisfação obtido para o serviço em estudo. No desenho do diagrama de causa e efeito, as setas representam o sentindo da influência de um determinante sobre outro (TINOCO; RIBEIRO, 2007).

\subsection{Identificação de atributos de qualidade percebida}

A segunda fase contempla a identificação e hierarquização dos atributos que afetam a qualidade percebida pelo cliente. Primeiramente, por meio de pesquisas na literatura e levantamento com usuários e especialistas deste tipo de serviço, são identificados os atributos da qualidade. Depois de identificados esses itens, cria-se o instrumento de pesquisa para a hierarquização dos atributos de qualidade importantes para os clientes desse tipo de serviço. No desenho do instrumento, recomenda-se que os atributos selecionados sejam organizados em grupos, a partir de características e do setor do serviço em que ele seria percebido pelo cliente, com o intuito de facilitar o raciocínio dos respondentes. Ao entrevistado é solicitado que, dentro de cada grupo, indique os três atributos que considera mais importantes, ordenando-os por importância. Da mesma forma, o respondente deve indicar e ordenar os três grupos mais importantes. Com isso, é possível determinar a importância geral de cada atributo.

\section{Estudo aplicado}

\subsection{Resultados referentes aos determinantes de satisfação}

Após a coleta dos dados, foi feita a contagem das respostas para cada relação investigada, e os resultados foram compilados em uma matriz que é apresentada na Tabela 1.

Analisando-se os resultados da primeira linha, pode-se observar que cinco (5) respondentes apontaram que a imagem corporativa de uma empresa bancária depende dos desejos pessoais; dez (10) clientes assinalaram que a imagem depende das expectativas; doze (12) apontaram que as emoções vivenciadas no momento da prestação do serviço influenciam diretamente a imagem; imagem dependente da qualidade percebida foi apontada por trinta e quatro

Tabela 1. Contagem das respostas dos questionários referentes aos determinantes.

\begin{tabular}{llccccccccc}
\hline \multicolumn{10}{c}{ Variáveis independentes } \\
\hline \multicolumn{1}{c}{ Serviços bancários } & Imagem & Desejos Expectativas & Emoções Qualidade Preço & Valor Confirmação Satisfação \\
\hline Variáveis & Imagem & - & 5 & 10 & 12 & 34 & 10 & 16 & 26 & 34 \\
dependentes & Desejos & 19 & - & 21 & 14 & 12 & 14 & 7 & 13 & 15 \\
& Expectativas & 36 & 25 & - & 3 & 14 & 19 & 10 & 12 & 7 \\
Emoções & 10 & 25 & 14 & - & 22 & 7 & 11 & 27 & 22 \\
Qualidade & 8 & 4 & 11 & 14 & - & 7 & 21 & 40 & 36 \\
Preço & 18 & 10 & 8 & 5 & 15 & - & 20 & 12 & 13 \\
Valor & 5 & 9 & 10 & 17 & 28 & 33 & - & 31 & 29 \\
Confirmação & 4 & 13 & 28 & 20 & 21 & 2 & 15 & - & 35 \\
Satisfação & 3 & 18 & 13 & 19 & 34 & 6 & 28 & 39 & - \\
\hline
\end{tabular}


(34) respondentes; e assim por diante. Essa mesma leitura pode ser feita para as demais linhas da matriz.

A partir das contagens apresentadas na Tabela 1, foram calculados os resíduos padronizados por meio da Equação 1. Esses valores estão apresentados na Tabela 2, na qual foram destacados os resíduos padronizados maiores do que $+2,00$, indicando as relações estatisticamente significativas entre as variáveis, para um nível de confiança de 0,05.

Apoiado nas relações significativas, elaborou-se o diagrama de causa e efeito que oferece uma representação visual da dependência entre os determinantes. O modelo de satisfação para serviços bancários traz diversos níveis de relacionamento entre os determinantes, bem como diversas formas de relação, pois algumas variáveis se relacionam mutuamente, como pode ser visto na Figura 2.

$\mathrm{O}$ modelo obtido indica a existência de forte relação entre satisfação do consumidor, confirmação de expectativas e qualidade percebida. Esse enlace triangular formado pelos determinantes é considerado a base do modelo de satisfação, uma vez que a qualidade percebida e a confirmação de expectativas têm grande influência sobre a satisfação do consumidor que, por sua vez, influencia mutuamente a qualidade percebida e a confirmação de expectativas. Sendo assim, um aumento na qualidade percebida, por exemplo, gera maior satisfação nos consumidores, que reciprocamente percebem uma qualidade maior no serviço. Da mesma forma, a maior confirmação das

Tabela 2. Resíduos padronizados.

Variáveis independentes

\begin{tabular}{llcccccccccc}
\hline \multicolumn{2}{c}{ Serviços bancários } & \multicolumn{1}{c}{ Imagem Desejos Expectativas } & Emoções & Qualidade & Preço & Valor Confirmação Satisfação \\
\hline Variáveis & Imagem & & $-3,26$ & $-1,91$ & $-1,36$ & 4,73 & $-1,90$ & $-0,29$ & 2,52 & 4,76 \\
dependentes & Desejos & 0,52 & & 1,05 & $-0,81$ & $-1,39$ & $-0,81$ & $-2,70$ & $-1,13$ & $-0,57$ \\
& Expectativas & 5,06 & 2,13 & & $-3,76$ & $-0,85$ & 0,52 & $-1,91$ & $-1,41$ & $-2,80$ \\
& Emoções & $-1,89$ & 2,14 & $-0,82$ & & 1,38 & $-2,69$ & $-1,64$ & 2,79 & 1,38 \\
Qualidade & $-2,43$ & $-3,52$ & $-1,64$ & $-0,82$ & & $-2,70$ & 1,07 & 6,45 & 5,31 \\
Preço & 0,25 & $-1,87$ & $-2,40$ & $-3,18$ & $-0,56$ & & 0,79 & $-1,40$ & $-1,12$ \\
Valor & $-3,27$ & $-2,19$ & $-1,93$ & $-0,02$ & 3,08 & 4,32 & & 3,96 & 3,38 \\
Confirmação & $-3,51$ & $-1,09$ & 2,95 & 0,79 & 1,10 & $-4,03$ & $-0,56$ & & 5,02 \\
Satisfação & $-3,81$ & 0,26 & $-1,11$ & 0,53 & 4,76 & $-2,99$ & 3,00 & 6,23 & \\
\hline
\end{tabular}

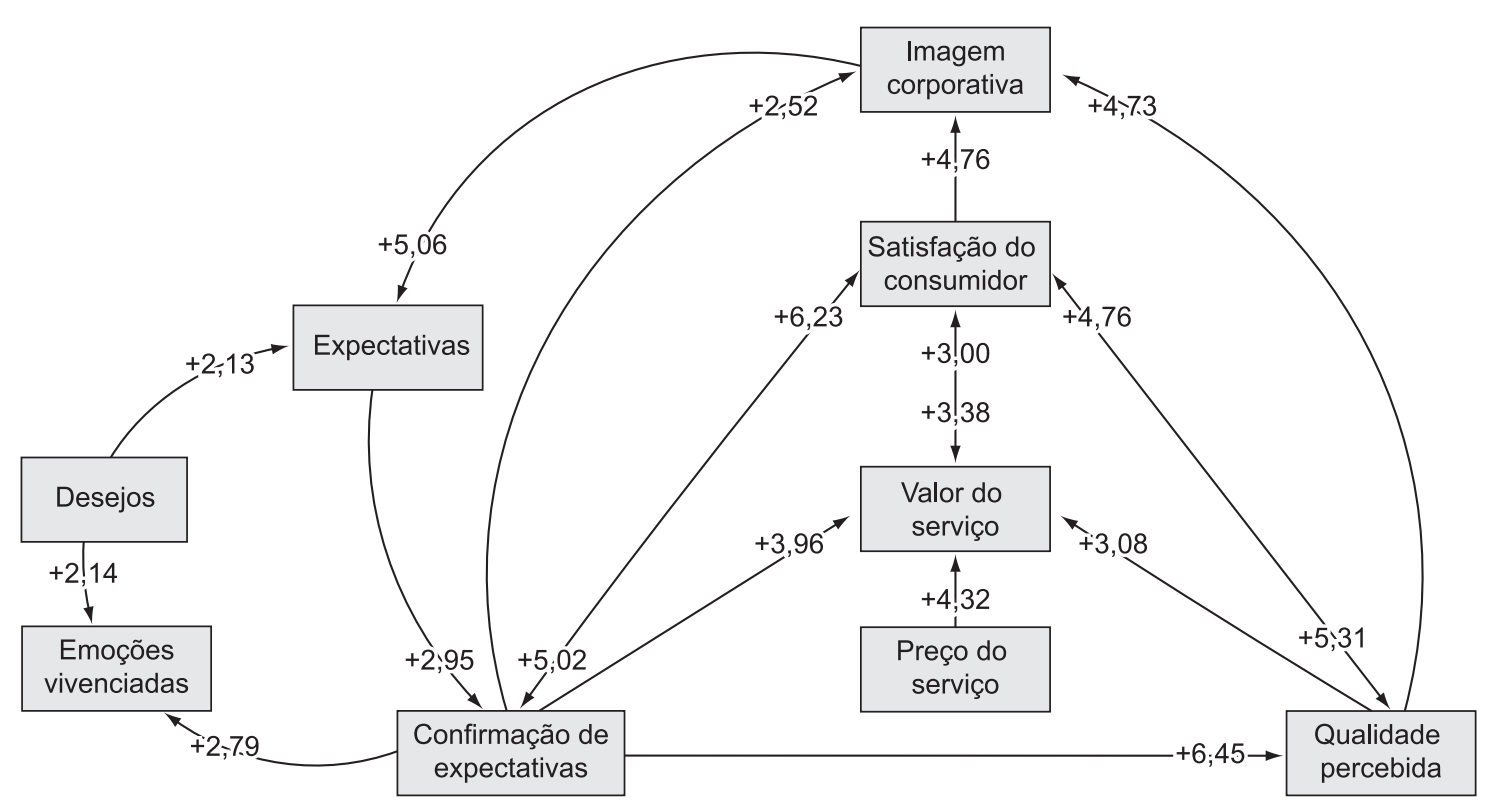

Figura 2. Modelo de relacionamento entre os determinantes da satisfação para serviços bancários. Fonte: Elaborada pelos autores. 
expectativas aumenta a satisfação do consumidor, que reforça a confirmação das expectativas. Percebe-se que esse triângulo também é a base do modelo de satisfação de clientes de restaurantes à la carte, proposto por Tinoco e Ribeiro (2007) (apresentado na Figura 1). Contudo, para serviços bancários, a confirmação de expectativas influencia a qualidade percebida, mas não é afetada reciprocamente, e essa é a relação mais forte do modelo, com um resíduo padronizado de $+6,45$.

Analisando-se o modelo da Figura 2, percebe-se a existência de outro enlace: imagem corporativa, expectativas, confirmação das expectativas, satisfação do consumidor e qualidade percebida. Isto é, a imagem da organização gera expectativas no consumidor que, ao serem confirmadas e superadas na prestação do serviço, geram satisfação e qualidade percebida, as quais reforçam a imagem coorporativa, fechando o enlace. Pode-se perceber também, que os desejos do cliente (mais próximos do lado emocional) e a confirmação de expectativas (mais próxima do lado racional) influenciam as emoções vivenciadas. Além disso, nota-se que as expectativas dos clientes são formadas pelos seus desejos pessoais e pela imagem corporativa da empresa. O preço é um determinante que influencia a avaliação do valor do serviço, feita pelo cliente ao comparar os custos (preço percebido) aos benefícios (qualidade percebida). Neste estudo envolvendo serviços bancários, o preço percebido não revelou dependência de nenhum dos demais determinantes. Talvez isso seja reflexo do fato de que a cobrança de tarifas bancárias foi recentemente regulamentada no Brasil, e os clientes ainda não possuem sensibilidade para avaliar preços dos serviços bancários.

\subsection{Resultados referentes aos atributos de qualidade}

A identificação dos atributos que afetam a qualidade percebida foi realizada por meio de pesquisas na literatura e levantamento com usuários e especialistas deste tipo de serviço. A lista consolidada é apresentada na Tabela 3.

Identificados esses itens, criou-se o instrumento de pesquisa para a hierarquização dos atributos importantes para os clientes desse tipo de serviço (ver Apêndice A). Na elaboração do questionário de pesquisa, para facilitar e qualificar as respostas, os atributos selecionados foram organizados em grupos, conforme a afinidade. Os grupos contemplados foram:

Aspectos externos - envolvendo as características físicas do local de prestação do serviço; Aspectos internos - considerando o ambiente interno, a qualidade dos atributos e pessoal envolvido; Atendimento - contendo os itens presentes na prestação do serviço e no envolvimento do cliente, explorando o comportamento dos funcionários; Confiabilidade e eficiência - possuindo as variáveis que são responsáveis por um serviço seguro e correto com o cliente; e Produtos oferecidos - abordando os itens característicos do setor bancário, explorando a oferta de produtos pela empresa.

Os respondentes indicaram os atributos mais importantes em cada grupo e, também, os grupos mais importantes. No que se refere à hierarquização dos grupos, foi feita a soma dos inversos das posições

Tabela 3. Atributos que afetam a qualidade percebida em serviços bancários.

\begin{tabular}{ll}
\hline Funcionários com conhecimento e habilidade devidos & Disponibilidade de estacionamento \\
Serviço feito corretamente na primeira vez & Cortesia dos atendentes \\
Tarifas bancárias baratas & Boa gama de serviços \\
Transparência e lealdade nas negociações & Funcionários não forçam a venda do produto \\
Funcionários buscam tornar o serviço mais ágil & Taxa de juros compatível \\
Sigilo bancário & Segurança adequada sem ser ostensiva \\
Funcionários em número apropriado (filas pequenas) & Interesse em saber as necessidades do cliente \\
Variedade de formas de acesso ao serviço & Agência climatizada \\
Serviço concluído dentro do prazo & Auxílio para o uso de caixas eletrônicos \\
Localização apropriada & Agência de fácil visualização \\
Eficiência na reparação de erros cometidos & Agência ampla, limpa e bem organizada \\
Disposição do funcionário para fazer o atendimento & Acesso para portadores de necessidades especiais \\
Atendimento personalizado e individualizado & Diversidade em opções de crédito \\
Facilidades proporcionadas pelos equipamentos do banco & Banheiros para os clientes \\
Funcionários transmitem confiança & Disponibilidade de guarda-volumes \\
Cadeiras para quem aguarda atendimento & Funcionários com boa aparência e vestidos adequadamente \\
\hline
\end{tabular}

Fonte: Elaborado pelos autores a partir de Blanchard e Galloway (1994); Zineldin (1996); Johnston (1997); Bahia e Nantel (2000); Newman (2001); Arasli, Mehtap-Smadi e Katircioglu (2005); e Glaveli et al. (2006). 
indicadas em cada questionário, ou seja, onde o respondente marcava os três grupos mais importantes numerando-os 1,2 e 3 , foram atribuídos pesos para cada um desses grupos na forma inversa, e o item mais importante recebeu peso 3. Somando-se o total de pesos recebidos nos 50 questionários, foi possível determinar a influência de cada grupo na qualidade percebida pelos clientes de serviços bancários. Os resultados aparecem na Tabela 4.

Os atributos pertencentes a cada grupo foram ponderados seguindo o mesmo procedimento: identificação dos atributos mais importantes em cada grupo, atribuindo-se a eles pesos 3, 2 e 1, e somando-se as pontuações associadas a todos os respondentes. Dessa forma, cada atributo tem uma importância dentro do seu grupo e uma importância global, ponderada a partir da importância do grupo ao qual ele pertence. Os resultados aparecem na Tabela 5.

Para analisar o impacto desses atributos na qualidade percebida pelo cliente foi utilizada a técnica de Pareto. Assim, os itens foram dispostos em forma decrescente de acordo com o seu percentual global de importância, e foi feita a soma acumulada desses percentuais. Como pode ser visto na Tabela 6 , quinze itens são responsáveis por 77,2\% do somatório total dos escores ponderados, representando os itens destacados dentre os atributos de qualidade percebida pelos clientes para o serviço em estudo.

Os resultados apresentam algumas semelhanças e divergências com a literatura. Como principais semelhanças, a exatidão do serviço, aqui abordada como serviço feito corretamente na primeira vez e o conhecimento sobre o serviço receberam alta importância para a qualidade percebida, como apontam Mersha e Adlakha (1991) e Zineldin (1996). Ainda, considerando a eficiência e agilidade das transações, atributos como empregados eficientes e velocidade do atendimento também aparecem entre os principais itens nos estudos de Blanchard e Galloway (1994), Bloemer, Ruyter e Peeters (1998) e Guo, Duff e Hair (2008). Alguns aspectos tangíveis como o ambiente e a aparência da agência foram aqui julgados como atributos de menor importância, assim como a aparência dos funcionários. Esse julgamento também

Tabela 4. Resultado referente à importância relativa dos grupos de atributos da qualidade.

\begin{tabular}{lc}
\hline \multicolumn{1}{c}{ Grupo } & Valor \\
\hline Aspectos externos & $9 \%$ \\
Aspectos internos & $12 \%$ \\
Atendimento & $29 \%$ \\
Confiabilidade e eficiência & $31 \%$ \\
Produtos oferecidos & $19 \%$ \\
\hline
\end{tabular}

Fonte: Elaborada pelos autores. está presente nos trabalhos de Mersha e Adlakha (1991), Blanchard e Galloway (1994) e Guo, Duff e Hair (2008).

Como principais divergências, a cortesia dos atendentes e a forma de tratar o cliente foram julgadas como atributos de menor importância, distinguindo-se claramente dos resultados apontados nas pesquisas de Blanchard e Galloway (1994), Zineldin (1996) e Guo, Duff e Hair (2008), nas quais esse quesito é apontado nos principais atributos. Nas pesquisas desses autores, em detrimento de funcionários com conhecimento e habilidade devidos e tarifas bancárias baratas, a cordialidade e a educação foram consideradas itens de maior importância para a percepção de qualidade do cliente. De certa forma, a capacidade dos funcionários de fornecer exatidão na prestação de serviço ainda é vista como um atrativo de grande impacto para o cliente nos países em desenvolvimento, como o Brasil. Porém, em países desenvolvidos, esse critério tende a ser considerado como obrigatório, atribuindo, assim, uma importância intermediária ou pequena.

As tarifas bancárias representam uma das formas de competição entre os bancos. No entanto, somente esse fator dificilmente irá determinar a adesão ou não de um cliente, uma vez que a alta competitividade do setor bancário causa um equilíbrio nesse quesito, fazendo com que as empresas necessitem ofertar maiores atrativos aos clientes. A velocidade e eficácia do atendimento (com influência no tamanho das filas na agência) são atrativos que podem ser diretamente visualizados pelos clientes, fazendo com que o cliente perceba um maior ou menor sacrifício para adquiri-lo. Entre os 32 atributos avaliados na pesquisa, percebe-se que oito (8) são responsáveis por mais de $50 \%$ da qualidade percebida. Esses itens pertencem, em sua maioria, aos grupos de confiabilidade e eficiência, atendimento e produtos oferecidos, ressaltando o grande impacto que esses quesitos têm na percepção da qualidade do serviço. Assim, os responsáveis por serviços bancários deveriam dedicar maior atenção aos atributos desses grupos.

A maior parte dos atributos pesquisados neste estudo poderia ser alocada nos cinco grupos da escala SERVQUAL: Aspectos Tangíveis, Confiabilidade, Presteza, Segurança e Empatia. Porém, para alocar a totalidade dos itens, seria necessário considerar um sexto grupo, contemplando especificamente serviços bancários. Observa-se que a escala SERVQUAL possui uma abordagem genérica, impossibilitando que alguns atributos de caráter técnico sejam alocados em algum dos cinco grupos.

Considerando os seis grupos mencionados, localização apropriada, variedade de formas de acesso ao serviço e facilidades proporcionadas pelos equipamentos do banco são os principais atributos de aspecto tangível; serviço feito corretamente na primeira vez, transparência e lealdade nas negociações, serviço 
Tabela 5. Importância dos atributos: percentuais relativos e globais.

\begin{tabular}{|c|c|c|}
\hline Atributos de qualidade percebida & Percentual relativo ao grupo & Percentual global \\
\hline \multicolumn{3}{|l|}{ Aspectos externos } \\
\hline Localização apropriada & $47 \%$ & $4,20 \%$ \\
\hline Disponibilidade de estacionamento & $23 \%$ & $2,07 \%$ \\
\hline Agência de fácil visualização & $13 \%$ & $1,20 \%$ \\
\hline Acesso para portadores de necessidades especiais & $10 \%$ & $0,87 \%$ \\
\hline Disponibilidade de guarda-volumes & $2 \%$ & $0,18 \%$ \\
\hline \multirow[t]{2}{*}{ Banheiros para os clientes } & $5 \%$ & $0,48 \%$ \\
\hline & & $9,00 \%$ \\
\hline \multicolumn{3}{|l|}{ Aspectos internos } \\
\hline Funcionários em número apropriado (filas pequenas) & $44 \%$ & $5,28 \%$ \\
\hline Cadeiras para quem aguarda atendimento & $19 \%$ & $2,24 \%$ \\
\hline Segurança adequada sem ser ostensiva & $14 \%$ & $1,72 \%$ \\
\hline Agência climatizada & $12 \%$ & $1,48 \%$ \\
\hline Agência ampla, limpa e bem organizada & $9 \%$ & $1,12 \%$ \\
\hline \multirow[t]{2}{*}{ Funcionários com boa aparência e vestidos adequadamente } & $1 \%$ & $0,16 \%$ \\
\hline & & $12,00 \%$ \\
\hline \multicolumn{3}{|l|}{ Atendimento } \\
\hline Funcionários com conhecimento e habilidade devidos & $31 \%$ & $8,99 \%$ \\
\hline Funcionários buscam tornar o serviço mais ágil & $20 \%$ & $5,90 \%$ \\
\hline Disposição do funcionário para fazer o atendimento & $13 \%$ & $3,77 \%$ \\
\hline Atendimento personalizado e individualizado & $12 \%$ & $3,38 \%$ \\
\hline Cortesia dos atendentes & $7 \%$ & $2,03 \%$ \\
\hline Funcionários não forçam a venda do produto & $7 \%$ & $1,93 \%$ \\
\hline Interesse em saber as necessidades do cliente & $5 \%$ & $1,55 \%$ \\
\hline \multirow[t]{2}{*}{ Auxílio para o uso de caixas eletrônicos } & $5 \%$ & $1,45 \%$ \\
\hline & & $29,00 \%$ \\
\hline \multicolumn{3}{|l|}{ Confiabilidade e eficiência } \\
\hline Serviço feito corretamente na primeira vez & $26 \%$ & $8,06 \%$ \\
\hline Transparência e lealdade nas negociações & $20 \%$ & $6,30 \%$ \\
\hline Sigilo bancário & $17 \%$ & $5,37 \%$ \\
\hline Serviço concluído dentro do prazo & $14 \%$ & $4,34 \%$ \\
\hline Eficiência na reparação de erros cometidos & $13 \%$ & $3,93 \%$ \\
\hline \multirow[t]{2}{*}{ Funcionários transmitem confiança } & $10 \%$ & $3,00 \%$ \\
\hline & & $31,00 \%$ \\
\hline \multicolumn{3}{|l|}{ Produtos oferecidos } \\
\hline Tarifas bancárias baratas & $36 \%$ & $6,78 \%$ \\
\hline Variedade de formas de acesso ao serviço & $25 \%$ & $4,75 \%$ \\
\hline Facilidades proporcionadas pelos equipamentos do banco & $17 \%$ & $3,17 \%$ \\
\hline Boa gama de serviços & $10 \%$ & $1,96 \%$ \\
\hline Taxa de juros compatível & $9 \%$ & $1,77 \%$ \\
\hline \multirow[t]{2}{*}{ Diversidade em opções de crédito } & $3 \%$ & $0,57 \%$ \\
\hline & & $19,00 \%$ \\
\hline
\end{tabular}

Fonte: Elaborada pelos autores.

concluído dentro do prazo e eficiência na reparação de erros cometidos são os principais atributos de confiabilidade; funcionários que buscam tornar o serviço mais ágil, funcionários em número apropriado (filas pequenas) e disposição do funcionário para fazer o atendimento são os mais importantes atributos para presteza; funcionários com conhecimento e habilidade devidos, sigilo bancário e funcionários que transmitem confiança têm maior destaque no grupo segurança; atendimento personalizado e individualizado e cortesia 
Tabela 6. Atributos mais importantes representando $77,21 \%$ do acumulado total.

\begin{tabular}{clcc}
\hline Ranking & \multicolumn{1}{c}{ Atributo } & Percentual global & Soma acumulada \\
\hline 1 & Funcionários com conhecimento e habilidade devidos & $8,99 \%$ & $8,99 \%$ \\
2 & Serviço feito corretamente na primeira vez & $8,06 \%$ & $17,05 \%$ \\
3 & Tarifas bancárias baratas & $6,78 \%$ & $23,83 \%$ \\
4 & Transparência e lealdade nas negociações & $6,30 \%$ & $30,13 \%$ \\
5 & Funcionários buscam tornar o serviço mais ágil & $5,90 \%$ & $36,03 \%$ \\
6 & Sigilo bancário & $5,37 \%$ & $41,40 \%$ \\
7 & Funcionários em número apropriado (filas pequenas) & $5,28 \%$ & $46,68 \%$ \\
8 & Variedade de formas de acesso ao serviço & $4,75 \%$ & $51,43 \%$ \\
9 & Serviço concluído dentro do prazo & $4,34 \%$ & $55,77 \%$ \\
10 & Localização apropriada & $4,20 \%$ & $59,97 \%$ \\
11 & Eficiência na reparação de erros cometidos & $3,93 \%$ & $63,90 \%$ \\
12 & Disposição do funcionário para fazer o atendimento & $3,77 \%$ & $67,67 \%$ \\
13 & Atendimento personalizado e individualizado & $3,38 \%$ & $71,05 \%$ \\
14 & Facilidades proporcionadas pelos equipamentos do banco & $3,17 \%$ & $74,22 \%$ \\
15 & Funcionários transmitem confiança & $3,00 \%$ & $77,21 \%$ \\
\hline
\end{tabular}

Fonte: Elaborada pelos autores.

dos atendentes configuram o grupo empatia. Boa gama de produtos e serviços e tarifas bancárias baratas, apesar de não serem os mais destacados entre os itens específicos do serviço em estudo, são atributos de relativa importância que não podem ser alocados em nenhum dos grupos anteriores, configurando, então, o grupo de produtos bancários.

Dentre as principais implicações teóricas deste trabalho destaca-se a contribuição dos resultados obtidos com as pesquisas desenvolvidas no setor de serviços, especificamente no segmento de serviços bancários. Os resultados obtidos neste trabalho confirmam algumas pesquisas da literatura, podendo ser destacados: i) o forte relacionamento entre satisfação de clientes e qualidade percebida (e.g., CRONIN Jr.; BRADY; HULT, 2000) e confirmação de expectativas (e.g., OLIVER, 1980; CHURCHILL; SURPRENANT, 1982; YI, 1993); e ii) a importância de alguns atributos como exatidão do serviço, conhecimento, eficiência e velocidade de atendimento sobre a qualidade percebida, também priorizados nas pesquisas de Mersha e Adlakha (1991), Blanchard e Galloway (1994), Bloemer, Ruyter e Peeters (1998) e Guo, Duff e Hair (2008).

Por outro lado, os achados desta pesquisa complementam estudos da literatura, por meio da identificação de novas relações entre determinantes da satisfação de clientes não consideradas nos modelos encontrados na literatura, como por exemplo, o impacto da imagem corporativa nas expectativas dos clientes, a influência da confirmação de expectativas nas emoções vivenciadas e no valor percebido pelo cliente e a influência dos desejos pessoais na formação de expectativas e nas emoções vivenciadas pelos clientes de serviços bancários. Além disso, o estudo das relações entre determinantes da satisfação de clientes e dos principais atributos de qualidade percebida para o serviço avaliado apresenta uma maior abrangência em relação às pesquisas da literatura, uma vez que as listas de determinantes e atributos de qualidade selecionados para avaliação contemplam os resultados de diversos estudos encontrados na literatura.

Como implicação prática, o modelo de satisfação de clientes obtido e o desdobramento da qualidade percebida em atributos importantes para o cliente podem servir de ferramentas para auxiliar profissionais de serviços bancários para focar em aspectos do serviço priorizados pelos clientes, melhorar a qualidade dos serviços oferecidos e, em consequência, a satisfação desses clientes.

Desta forma, gestores de serviços bancários podem priorizar atributos de confiabilidade e eficiência e de atendimento de seus serviços para melhorar a percepção de qualidade dos clientes, que constitui o principal determinante da satisfação dos clientes de serviços bancários, conforme indicações da literatura e confirmação obtida nesta pesquisa. Além disso, os resultados sugerem que a influência de outros determinantes na satisfação de clientes de serviços bancários deve ser considerada na definição das políticas estratégicas da empresa. Por exemplo, a imagem que os clientes possuem do prestador de serviços afeta as expectativas prévias, as quais, ao serem confirmadas (ou não), podem gerar satisfação (ou não) nesses clientes. Assim, a propaganda deve ser corretamente dimensionada, divulgando serviços que o banco pode atender adequadamente. Propaganda exagerada irá criar falsas expectativas nos clientes, afetando a sua satisfação após uso do serviço. 
Ainda considerando o ponto de vista prático, a lista de atributos hierarquizada, destacando aspectos como: conhecimento e habilidade dos funcionários, capacidade de fazer o serviço corretamente na primeira vez, tarifas bancárias competitivas, transparência e lealdade nas negociações, pode ser prontamente utilizada para direcionar esforços de melhoria em instituições bancárias. O desenvolvimento desses aspectos terá maior impacto sobre a qualidade percebida e a satisfação dos clientes do que o desenvolvimento de outros aspectos considerados de menor importância

\section{Conclusões}

Entre os resultados do modelo de satisfação desenvolvido neste trabalho, destacam-se: i) a forte relação entre satisfação, confirmação de expectativas e qualidade percebida; ii) a imagem da organização gerando expectativas no consumidor que, ao serem confirmadas, geram satisfação e qualidade percebida, e essas reforçam novamente a imagem corporativa; iii) os desejos do cliente (mais próximos do lado emocional) e a confirmação de expectativas (mais próxima do lado racional) influenciando as emoções vivenciadas no momento da prestação do serviço; iv) as expectativas dos clientes formadas pelos seus desejos pessoais e pela imagem corporativa da empresa; e v) o valor do serviço construído a partir do preço percebido, qualidade percebida e confirmação das expectativas. Entre os 32 atributos de qualidade percebida avaliados, os oito principais são responsáveis por mais de $50 \%$ da qualidade. São eles: funcionários com conhecimento e habilidade devidos, serviço feito corretamente na primeira vez, tarifas bancárias baratas, transparência e lealdade nas negociações, funcionários buscam tornar o serviço mais ágil, sigilo bancário, funcionários em número apropriado (filas pequenas) e variedade de formas de acesso ao serviço.

Analisando-se conjuntamente os resultados das duas pesquisas, fica evidente a importância da qualidade percebida na avaliação do serviço, especificamente na satisfação do cliente, na imagem da empresa e no valor do serviço. Isto pode ser observado pelo forte relacionamento obtido entre esses determinantes no modelo de satisfação. Logo, um aprimoramento na qualidade percebida, que pode ser obtido por meio de ações que desenvolvam os principais atributos para serviços bancários, listados no parágrafo anterior, deve conduzir a melhorias na satisfação do consumidor, na imagem corporativa e no valor do serviço, caracterizando, dessa forma, uma importante ferramenta para que os responsáveis por serviços bancários possam prestar um serviço diferenciado.

Entre as principais limitações deste trabalho podem ser destacadas: i) o uso de uma amostra não estratificada em função do tipo de cliente ou serviço oferecido pelos bancos; e ii) a delimitação geográfica, uma vez que a amostra pesquisada foi constituída por moradores da cidade de Porto Alegre. Sugere-se para trabalhos futuros a reaplicação do estudo considerando segmentos específicos de clientes do setor financeiro. O modelo apresentado neste trabalho caracteriza um quadro geral estabelecendo uma referência para o setor. Estudos de segmentos específicos ajudariam a aprofundar o conhecimento dos serviços bancário.

\section{Referências}

ANDREASSEN, T. W.; LINDESTAD, B. Customer loyalty and complex services - The impact of corporate image on quality, customer satisfaction and loyalty for customers with varying degrees of service expertise. International Journal of Service Industry Management, v. 9, n. 1, p. 7-23, 1998.

ARASLI, H.; MEHTAP-SMADI, S.; KATIRCIOGLU, S. T. Customer service quality in the Greek Cypriot banking industry. Managing Service Quality, v. 15, n. 1, p. 41-56, 2005.

AVKIRAN, N. K. Developing an instrument to measure customer service quality in branch banking. International Journal of Bank Marketing, v. 12, n. 6, p. 10-18, 1994.

BAHIA, K.; NANTEL, J. A reliable and valid measurement scale for the perceived service quality of banks. International Journal of Bank Marketing, v. 18, n. 2, p. 84-91, 2000.

BEARDEN, W. O.; TEEL, J. E. Selected determinants of consumer satisfaction and complaint reports. Journal of Marketing Research, v. 20, p. 21-28, 1983.

BEI L.-T.; CHIAO, Y.-C. An integrated model for the effects of perceived product, perceived service quality, and perceived price fairness on consumer satisfaction and loyalty. Journal of Consumer Satisfaction, Dissatisfaction and Complaining Behavior, v. 14, 2001.

BLANCHARD, R. F.; GALLOWAY, R. L. Quality in retail banking. International Journal of Service Industry Management, v. 5, n. 4, p. 5-23, 1994.

BLOEMER, J.; RUYTER, K.; PEETERS, P. Investigating drivers of bank loyalty: the complex relationship between image, service quality and satisfaction. International Journal of Bank Marketing, v. 16, n. 7, p. 276-286, 1998.

CADOTTE, E. R.; WOODRUFF, R. B.; JENKINS, R. L. Expectations and norms in models of consumer satisfaction. Journal of Marketing Research, v. 24, p. 305-314, 1987.

CHOI, K.-S. et al. The relationships among quality, value, satisfaction and behavioral intention in health care provider choice: a South Korean study. Journal of Business Research, v. 57, p. 913-921, 2004.

CHURCHILL Jr., G. A.; SURPRENANT, C. An investigation into the determinants of customer satisfaction. Journal of Marketing Research, v. 19, p. 491-504, 1982.

CRONIN Jr., J. J.; BRADY, M. K.; HULT, G. T. Assessing the effects of quality, value and customer satisfaction on 
consumer behavioral intentions in service environments. Journal of Retailing, v. 76, n. 2, p. 193-218, 2000.

CRONIN, J. J.; TAYLOR, S. A. Measuring service quality: a reexamination and extension. Journal of Marketing, v. 56, n. 3, p. 55-68, 1992.

DAY, E. The role of value in consumer satisfaction. Journal of Consumer Satisfaction, Dissatisfaction and Complaining Behavior, v. 15, 2002.

FEDERAÇÃO BRASILEIRA DE BANCOS - FEBRABAN. Relatório Social 2006. São Paulo. 2006 Disponível em: <http://www.febraban.org.br/Febraban.asp?id_ pagina=90 > . Acesso em: 10 fev. 2009.

FEDERAÇÃO BRASILEIRA DE BANCOS - FEBRABAN. Relatório Social 2007. São Paulo. 2007 Disponível em: <http://www.febraban.org.br/Febraban.asp?id_ pagina=90 $>$. Acesso em: 10 fev.2009.

FITZSIMMONS, J. A.; FITZSIMMONS, M. Administração de serviços: operações, estratégia tecnologia de informação. 2.ed. Porto Alegre: Bookman, 2000.

FORNELL, C. et al. The american customer satisfaction index: nature, purpose, and findings. Journal of Marketing, v. 60, n. 4, p. 7-12, 1996.

GALLOWAY, R. L.; BLANCHARD, R. F. Variation in the perception of quality with lifestage in retail banking. International Journal of Bank Marketing, v. 14, n. 1, p. 22-29, 1996.

GLAVELI, N.; PETRIDOU, E.; LIASSIDES, C.; SPATHIS, C. Bank service quality: evidence from five Balkan countries. Managing Service Quality, v. 16, n. 4, p. 380-394, 2006.

GRONROOS, C. A. Service quality model and its marketing implications. European Journal of Marketing, v. 18, n. 4, p. 36-44, 1984.

GUO, X.; DUFF, A.; HAIR, M. Service quality measurement in the Chinese corporate banking market. International Journal of Bank Marketing, v. 26, n. 5, p. 305-327, 2008.

JOHNSTON, R. Identifying the critical determinants of service quality in retail banking: importance and effect. International Journal of Bank Marketing, v. 15, n. 4, p. 111-116, 1997.

JUN, S. et al. The relative influence of affective experience on consumer satisfaction under positive versus negative discrepancies. Journal of Consumer Satisfaction, Dissatisfaction and Complaining Behavior, v. 14, p. 141-153, 2001.

KOTLER, P. Administração de marketing: análise, planejamento, implementação e controle. Traduzido por Ailton Bomfim Brandão. 5 ed. São Paulo: Atlas, 1998. 725 p.

KOTLER, P.; KELLER, K. L. Administração de marketing. 12. ed. São Paulo: Pearson Prentice Hall, 2006. 750 p.

LEVESQUE, T; McDOUGALL, G. H. G. Determinants of customer satisfaction in retail banking. International Journal of Bank Marketing, v. 14, n. 7, p. 12-20, 1996.

LOVELOCK, C.; WRIGHT, L. Serviços: marketing e gestão. São Paulo: Saraiva, 2001. 416 p.
MERSHA, T.; ADLAKHA, V. Attributes of service quality: the consumers' perspective. International Journal of Service Industry Management, v. 3, n. 3, p. 34-45, 1992.

MIGUEL, P. A. C.; SALOMI, G. E. Uma revisão dos modelos para medição da qualidade em serviços. Revista Produção, v. 14, n. 1, 2004.

NEWMAN, K. Interrogating SERVQUAL: a critical assessment of service quality measurement in a high street retail bank. International Journal of Bank Marketing, v. 19, n. 3, p. 126-139, 2001.

OLIVER, R. L. A cognitive model of the antecedents and consequences of satisfaction decisions. Journal of Marketing Research, v. 17, p. 460-469, 1980.

OLIVER, R. L. Cognitive, affective, and attribute bases of the satisfaction response. Journal of Consumer Research, v. 20, p. 418- 430, 1993.

PARASURAMAN, A.; ZEITHAML, V. A.; BERRY, L. L. A conceptual model of service quality and its implications for future research. Journal of Marketing, v. 49, n. 4, p. 41-50, 1985.

PARASURAMAN, A.; ZEITHAML, V. A.; BERRY, L. L. SERVQUAL: a multiple - item scale for measuring consumer perceptions. Journal of Retailing, v. 64, n. 1, p. 12-40, 1988.

SETH, N.; DESHMUKH, S. G.; VRAT, P. Service quality models: a review. International Journal of Quality \& Reliability Management, v. 22, n. 9, p. 913-949, 2005.

SHETH, J.; BANWARI, M.; NEWMAN, B. I. Comportamento do cliente: indo além do comportamento do consumidor. Traduzido por Lenita M. R. Esteves. São Paulo: Atlas, 2001. 795 p.

SPRENG, R. A.; MACKENZIE, S. B.; OLSHAVSKY, R. $W$. A reexamination of the determinants of consumer satisfaction. Journal of Marketing, v. 60, n. 3, p. 15-32, 1996.

TINOCO, M. A. Proposta de modelos de satisfação dos consumidores de serviços. 2006. Dissertação (Mestrado em Engenharia de Produção)-Universidade Federal do Rio Grande do Sul, 2006.

TINOCO, M. A.; RIBEIRO, J. L. Estudo qualitativo dos principais atributos que determinam a percepção de qualidade e de preço dos consumidores de restaurantes a la carte. Gestão e Produção, v. 15, n. 1, p. 73-87, 2008.

TINOCO, M. A.; RIBEIRO, J. L. Uma nova abordagem para a modelagem das relações entre os determinantes da satisfação dos clientes de serviços. Revista Produção, v. 17, n. 3, 2007.

YI, Y. The determinants of consumer satisfaction: the moderating role of ambiguity. Advances in Consumer Research, v. 20, p. 502-506, 1993.

ZEITHAML, V. A. Consumer perceptions of price, quality and value: a means-end model and synthesis of evidence. Journal of Marketing, v. 52, p. 2-22, 1988.

ZINELDIN, M. Bank strategic positioning and some determinants of bank selection. International Journal of Bank Marketing, v. 14, n. 6, p. 12-22, 1996. 


\section{Apêndice A - Questionário para hierarquização dos atributos de qualidade percebida}

Serviços bancários - atributos de qualidade percebida

Questionário número:

Com a finalidade de identificar os determinantes principais que afetam a qualidade percebida de um serviço bancário, solicita-se assinalar no questionário a seguir os três principais atributos de cada grupo, marcando "1" para o mais importante, "2" para o segundo item mais importante e " 3 " para o terceiro item classificado:

\section{Aspectos externos}

( ) Localização apropriada

( ) Disponibilidade de estacionamento

( ) Agência de fácil visualização

( ) Acesso para portadores de necessidades especiais

( ) Disponibilidade de guarda-volumes

( ) Banheiros para os clientes

\section{Aspectos internos}

( ) Agência ampla, limpa e bem organizada

( ) Agência climatizada

( ) Funcionários com boa aparência e vestidos adequadamente

( ) Funcionários em número apropriado (filas pequenas mesmo em horários de pico)

( ) Cadeiras para quem aguarda atendimento

( ) Segurança adequada sem ser ostensiva

\section{Atendimento}

( ) Auxílio para o uso de caixas eletrônicos

( ) Disposição do funcionário para fazer o atendimento

( ) Cortesia dos atendentes

( ) Interesse em saber as necessidades do cliente

( ) Funcionários com conhecimento e habilidade devidos

( ) Funcionários buscam tornar o serviço mais ágil

( ) Atendimento personalizado e individualizado

( ) Funcionários não forçam a venda do produto

\section{Confiabilidade e eficiência}

( ) Funcionários transmitem confiança

( ) Transparência e lealdade nas negociações
( ) Serviço feito corretamente na primeira vez

( ) Serviço concluído dentro do prazo

( ) Eficiência na reparação de erros cometidos

( ) Sigilo bancário

\section{Produtos oferecidos}

( ) Boa gama de serviços

( ) Tarifas bancárias baratas

( ) Diversidade em opções de crédito

( ) Taxa de juros compatível

( ) Variedade de formas de acesso ao serviço: internet, telefone, etc.

( ) Facilidades proporcionadas pelos equipamentos do banco

Há algum fator importante para a qualidade do serviço que não foi listado? Em caso afirmativo, indicar abaixo:

Solicita-se também que assinale, da mesma forma, os três principais grupos:
( ) Aspectos externos
( ) Aspectos internos
( ) Atendimento
( ) Confiabilidade e eficiência
( ) Produtos oferecidos 


\section{Anexo A - Questionário para identificação das relações entre os determinantes da satisfação}

Tipo de serviço: Serviços bancários

Número de questionário:

Com a finalidade de identificar os determinantes principais que afetam a satisfação dos clientes desse tipo de serviço, solicita-se responder o questionário a seguir, selecionando uma, várias ou nenhuma das alternativas:

1. A Imagem corporativa da empresa de serviço depende principalmente de:
a) Desejos pessoais
b) Expectativas
c) Emoções vivenciadas no momento
d) Qualidade percebida
e) Preço do serviço
f) Valor do serviço
g) Confirmação de expectativas
h) Satisfação gerada pelo serviço

2. Os Desejos pessoais dos clientes dependem principalmente de:
a) Imagem corporativa
b) Expectativas
c) Emoções vivenciadas no momento
d) Qualidade percebida
e) Preço do serviço
f) Valor do serviço
g) Confirmação de expectativas
h) Satisfação gerada pelo serviço

3. As Expectativas dos clientes dependem principalmente de:
a) Imagem corporativa
b) Desejos pessoais
c) Emoções vivenciadas no momento
d) Qualidade percebida
e) Preço do serviço
f) Valor do serviço
g) Confirmação de expectativas
h) Satisfação gerada pelo serviço

4. As Emoções vivenciadas no momento dependem principalmente de:
a) Imagem corporativa
b) Desejos pessoais
c) Expectativas
d) Qualidade percebida
e) Preço do serviço
f) Valor do serviço
g) Confirmação de expectativas
h) Satisfação gerada pelo serviço

5. A Qualidade percebida do cliente em relação ao serviço depende principalmente de:
a) Imagem corporativa
b) Desejos pessoais
c) Expectativas
d) Emoções vivenciadas no momento
e) Preço do serviço
f) Valor do serviço
g) Confirmação de expectativas
h) Satisfação gerada pelo serviço

6. O Preço do serviço depende principalmente de:
a) Imagem corporativa
b) Desejos pessoais
c) Expectativas
d) Emoções vivenciadas no momento
e) Qualidade percebida
f) Valor do serviço
g) Confirmação de expectativas
h) Satisfação gerada pelo serviço

7. O Valor do serviço depende principalmente de:
a) Imagem corporativa
b) Desejos pessoais
c) Expectativas
d) Emoções vivenciadas no momento
e) Qualidade percebida
f) Preço do serviço
g) Confirmação de expectativas
h) Satisfação gerada pelo serviço

8. A Confirmação de expectativas depende principalmente de:
a) Imagem corporativa
b) Desejos pessoais
c) Expectativas
d) Emoções vivenciadas no momento
e) Qualidade percebida
f) Preço do serviço
g) Valor do serviço
h) Satisfação gerada pelo serviço

9. A Satisfação gerada pelo serviço depende principalmente de:
a) Imagem corporativa
b) Desejos pessoais
c) Expectativas
d) Emoções vivenciadas no momento
e) Qualidade percebida
f) Preço do serviço
g) Valor do serviço
h) Confirmação de expectativas 


\section{Anexo B - Conceitos dos determinantes avaliados na pesquisa de satisfação}

\section{Definições dos determinans}

Imagem corporativa: percepção em relação à corporação ou empresa de serviços, fixada na memória dos consumidores.

Desejos pessoais: afã de obter mais satisfação do que é efetivamente necessário. Condição psicológica/ social insatisfatória que nos leva a uma ação para remediá-la.

Expectativas: crença prévia sobre o que o serviço irá oferecer. Construída a partir de experiências anteriores com o serviço, informação recebida por propaganda e comunicação boca a boca.

Emoções vivenciadas no momento: sentimentos positivos (ou negativos) vivenciados no momento da prestação de serviço. Sentimentos de felicidade, prazer, entusiasmo, alegria, bom humor (ou mau humor, tristeza, pesar, arrependimento, raiva, culpa).

Qualidade percebida: avaliação da excelência do serviço em relação às dimensões de confiabilidade, responsabilidade, segurança, empatia e tangíveis, conforme a percepção do cliente.

Preço do serviço: aquilo que é pago pelo serviço. Aquilo ao qual se renuncia ou que é sacrificado na obtenção de um serviço.

Valor do serviço: relação entre os benefícios obtidos e o preço do serviço. (custo / benefício).

Confirmação de expectativas: comparação entre o que esperávamos receber e o que percebemos que recebemos do serviço.

Satisfação gerada pelo serviço: estado afetivo gerado pela reação emocional à experiência com um serviço. 